\title{
Ecology and Water Supply Based Multi-objective Optimal Dispatch Model and Its Case Study in Yangtze basin
}

\author{
Xuemin Wang, Jianzhong Zhou, and Chao Wang
}

\begin{abstract}
The cascade reservoir dispatching based on the ecology and water supply is a new topic in recent years. This paper present the Ecology and Water-supply Based Multi-objective Optimal Dispatch Model (EWSB-MODM) with three objectives: ecological benefit, water supply benefit and power generation benefit. Then, by using the Monthly Frequency Computation method and considering the ecological factors (includes the breeding of Chinese sturgeon and the four major Chinese carps, preventing saltwater intrusion, avoiding dissolved gas supersaturation and the water level control of the Dongting and Poyang Lake), this paper defines the suitable ecological flow for the Three Gorges Cascade (TGC), which is taken as the ecological benefit criterion. Meanwhile, with a view to the situation of water demands and the local water shortage risks appearing in the upper and middle reaches of the Yangtze River, the water requirement is determined, and it is converted into the water supply rate as the criterion of the water supply benefits. Finally, this paper imports the multi-objective differential evolution algorithm (MODE) to solving the engineering case of the Three Gorges cascade. Results show that the model and method proposed in this paper can gain non inferior solution set which is uniform distributed and meets the ecological and water supply benefits, providing a scientific basis for reservoir schedulers to make the reasonable decision.
\end{abstract}

Index Terms-Ecology, water supply, power Generation, multi-objective optimal dispatch.

\section{INTRODUCTION}

The Yangtze River is the world's third largest river. The Three Gorges Cascade (TGC) is a key backbone cascade in the Yangtze River, which consists of the Three Gorges power station in the upper reaches and the Gezhouba power station in the lower reaches. The Three Gorges reservoir is the leading reservoir in the cascade, with the installed power capacity of 22.4 million $\mathrm{kW}$, the normal water level of $175 \mathrm{~m}$, flood water level of $145 \mathrm{~m}$ and the utilizable water capacity of 24.9 billion $\mathrm{m} 3$. For the Gezhouba power station, it has the installed power capacity of 2.71 million $\mathrm{kW}$, the normal water level of $66.5 \mathrm{~m}$, flood water level of $63 \mathrm{~m}$.

As the Three Gorges Cascade is a demarcation point of the upper and lower reaches of the Yangtze River, its operation inevitably pose a threat to the water supply security and ecosystem stability in a certain range of the river. In recent

Manuscript received March 31, 2015; revised June 13, 2015. This work is supported by the National Natural Science Foundation of China (NSFC) (No.51239004 and No.51109086).

Xuemin Wang and Chao Wang are with the School of Hydropower and Information Engineering, Huazhong University of Science and Technology, Wuhan 43007, China (e-mail: wang_xuemin@foxmail.com, c.wang1222@gmail.com).

Jianzhong Zhou is with the Hubei Key Laboratory of Digital Valley Science and Technology, Wuhan 430074, China (e-mail: jz.zhou@ @ust.cn). years, many researchers have carried out a series of studies around the issue of reservoir dispatch [1], suitable ecological flow [2], [3] and habitat research [4], [5].However, there are some problems in these researches: 1) For most ecological flow calculation methods, only the statistical law is considered, so the ecological hydrological characteristics of the river basin are ignored; 2) In the dispatch model, the evaluation criteria of water supply in the upstream is not described clearly, which makes it difficult to implement practically.

Based on the previous studies, this paper establishes the ecology and water supply-based multi-objective optimal dispatch model (EWSB-MODM). Then the criterions of the ecological benefit of the lower Yangtze Rive and the water supply in the upper Yangtze River are determined. At last, the Multi-objective difference evolution is used to solve the model.

\section{ECOLOGY AND WATER SUPPLY-BASED Multi-OBJECTIVE OPTIMAL DisPatCH MODEL} (EWSB-MODM)

To conduct the study, we clearly set three specific goals. First, the gross power generation of the cascade directly means the economic benefit, which is taken as one dispatching objective of this model. Secondly, this paper takes the ecological over-and-short water amount in the lower reaches of the cascade as the measurable indicator of the ecological benefit. Finally, we take the water supply rate as the third objective of this model.

\section{A. Objective Function}

Taking the maximum power generation of the cascade, the minimum ecological over-and-short water in the lower reaches and the maximum water supply rate as the objective in this model, the objective function of EWSB-MODM is expressed as follows:

1) Maximum power generation of the cascade

$$
\max f_{1}=\max E=\sum_{i=1}^{N u m} \sum_{t=1}^{T} K_{i} Q_{i, t}^{f} H_{i, t}^{f} \Delta t=\sum_{i=1}^{N u m} \sum_{t=1}^{T} N_{i, t} \Delta t
$$

2) Minimum ecological over-and-short water in the lower reaches of the cascade

$$
\min f_{2}=\min W^{Q}=\sum_{t=1}^{T}\left|Q_{t}^{X}-Q_{t}^{S}\right| \Delta t
$$

3) Maximum water supply rate

$$
\max f_{3}=\max D^{S}=\max \frac{W^{R}}{W^{S}}
$$


where $E$ is the power generation of the cascade; Num is the total number of power stations in the cascade; $T$ is the length of dispatch time; $K_{i}$ is the output factor of the $i$-th station; $Q_{i, t}^{f}$ is the generation discharge of the $i$-th station at the $t$-th period; $H_{i, t}^{f}$ is the water head; $N_{i, t}$ is the output; $\Delta t$ is the length of a single period; $W^{Q}$ is the amount of the ecological over-and-short water; $D^{S}$ is the water supply rate; $W^{R}$ is the amount of water demands in the upper reaches; $W^{S}$ is the actual supplied water; $Q_{t}^{X}$ is the outflow of the cascade; $Q_{t}^{S}$ is the suitable ecological flow of the downstream river.

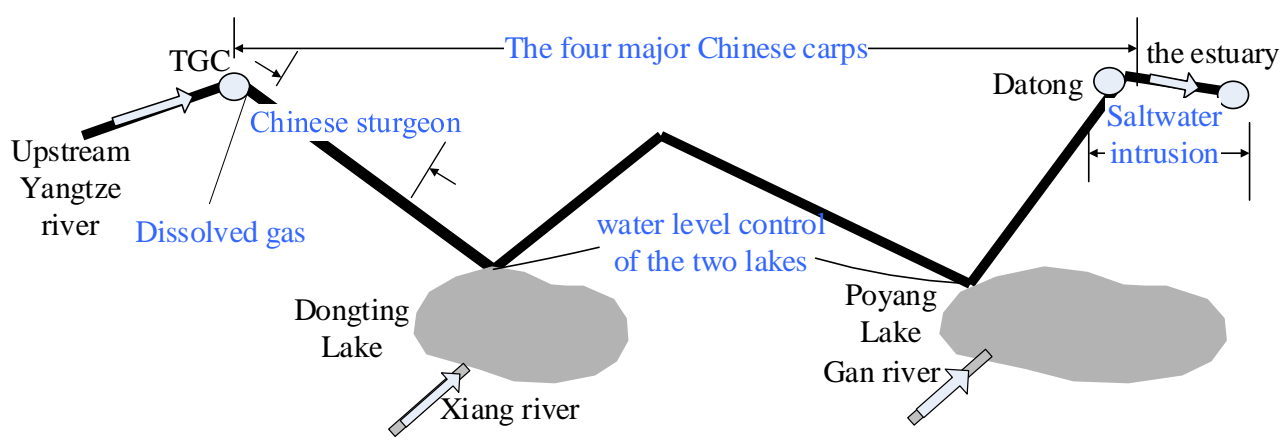

Fig. 1. Sketch map of the downstream Yangtze River.

\section{B. Model constraint}

The dispatch constraints of the cascade hydropower stations mainly includes water level constraints, water balance constraints, power output constraints and discharged flow constraints.

1) Water level constraints

$$
Z_{i, t}^{\min } \leq Z_{i, t} \leq Z_{i, t}^{\max }
$$

where $Z_{i, t}$ is the water level of the $i$-th power station at the $t$-th period; $Z_{i, t}^{\min }$ and $Z_{i, t}^{\max }$ respectively stand for the upper limit and lower limit of water level.

2) Power output constraints

$$
N_{i, t}^{\min } \leq N_{i, t} \leq N_{i, t}^{\max }
$$

where $N_{i, t}$ is the power output of the $i$-th power station during the $t$-th period; $N_{i, t}^{\min }$ and $N_{i, t}^{\max }$ respectively stand for the upper limit and lower limit of power output.

3) Flow constraint

$$
Q_{i, t}^{\min } \leq Q_{i, t}^{X} \leq Q_{i, t}^{\max }
$$

where $Q_{i, t}^{\min }$ is the discharge of the $i$-th power station during the $t$-th period; $Q_{i, t}^{\min }$ and $Q_{i, t}^{\max }$ respectively stand for the upper limit and lower limit of outflow.

4) Water balance constraints

$$
\begin{gathered}
V_{i, t+1}=V_{i . t}+\left(I_{i, t}-Q_{i, t}^{X}\right) \times \Delta t \\
I_{G, t}=Q_{S, t-\tau}^{X}+q_{t}
\end{gathered}
$$

where $V_{i . t}$ is the capacity of the $i$-th power station of the $t$-th period; $I_{i, t}$ is the inflow of the $i$-th power station; $\tau$ is the flow time; $I_{G, t}$ is the inflow of the power station in the lower reaches; $Q_{S, t-\tau}^{X}$ is the discharge flow of the power station in the upper reaches of the ( $t-\tau)$-th period; $q_{t}$ is the inflow of the river between these two power stations.

\section{ECOlOGICAL BENEFIT EVALUATION CRITERION}

The study object of this paper is the Three Gorges Cascade (TGC). The suitable ecological flow is defined by the Monthly frequency computation method (MFCM) and the ecological factors in the downstream.

\section{A. Monthly Frequency Computation Method (MFCM)}

The MFCM is to calculate a suitable ecological flow [2]. Each year is divided into abundant period, normal period and dry period according to historical runoff. Then the suitable ecological flow for each month is determined by the assurance rates of each period, and the same period possesses the same water assurance rate. For Yangtze River, the dry period includes January-April, the normal period includes May and October-December, the abundant period includes June-September. Then the frequency for each month (frequency of dry period 10\%, normal period $50 \%$ and abundant period 90\%) is adopted. The statistic results of MFCM are shown in Table I.

\section{B. Ecological Factors}

This paper selects some key ecological factors in the downstream of Yangtze River, as shown in Fig. 1, some of the information refers to [6].

1) Chinese sturgeon is the national first-grade endangered protection animal. The breeding season includes October and November, and the outflow of the TGC is required to be $12000 \mathrm{~m} 3 / \mathrm{s}$.

2) The four major Chinese carps are important economic species. The breeding season is from April to July, and the outflow is required to be $11000 \mathrm{~m}^{3} / \mathrm{s}$.

3) Saltwater intrusion. The saltwater intrusion refers that the high salinity water of the ocean pushes upstream along the estuary with the rising tide. During the period of reducing salinity at the estuary, the outflow is required to be $5500 \mathrm{~m} 3 / \mathrm{s}$ from December to April of the next year, but $10500 \mathrm{~m} 3 / \mathrm{s}$ in October and $7500 \mathrm{~m}^{3} / \mathrm{s}$ in November.

4) Saturation of the dissolved gas. When large water flow discharges through the dam's outlet, the dissolved gas in 
the water downstream increases sharply so that the fish reproduction is influenced. It is required that the discharged flow should be less than $30000 \mathrm{~m}^{3} / \mathrm{s}$.

5) Ecological water level control of the two lakes. The Dongting Lake and Poyang Lake are the habitats for precious fish and migratory birds, the lowest water level of the lakes are limited. It requires that the outflow is larger than $5500 \mathrm{~m}^{3} / \mathrm{s}$.

On the basis of comprehensively considering the water demands of the above typical ecological elements, we define the suitable ecological flow of the TGC as shown in Table I.

TABLE I: THE SUITABLE ECOLOGICAL FLOW OF THE TGC $\left(\mathrm{M}^{3} / \mathrm{s}\right)$

\begin{tabular}{|c|c|c|c|c|c|c|c|c|c|c|c|c|}
\hline month & 1 & 2 & 3 & 4 & 5 & 6 & 7 & 8 & 9 & 10 & 11 & 12 \\
\hline MFCM & 4989 & 4548 & 5458 & 8613 & 11884 & 13570 & 22240 & 19845 & 18143 & 19593 & 10382 & 5970 \\
\hline reduce salinity & 5500 & 5500 & 5500 & 5500 & & & & & & 10500 & 7500 & 5500 \\
\hline Chinese sturgeon & & & & & & & & & & 12000 & 12000 & \\
\hline The Four Major Carps & & & & 11000 & 11000 & 11000 & 11000 & & & & & \\
\hline Dissolved gas & \multicolumn{12}{|c|}{$<30000$} \\
\hline The Two Lakes & \multicolumn{12}{|c|}{$>5500$} \\
\hline Composite results & 5500 & 5500 & 5500 & 11000 & 11884 & 13570 & 22240 & 19845 & 18143 & 19593 & 12000 & 5970 \\
\hline
\end{tabular}

TABLE II: WATER DEMAND OF EACH MONTH IN 2020

\begin{tabular}{|c|c|c|c|c|c|c|}
\hline Month & 1 & 2 & 3 & 4 & 5 & 6 \\
\hline Total water demand $\left(10^{6} \mathrm{~m}^{3}\right)$ & 2994.04 & 2990.88 & 3713.48 & 3643.27 & 6381.12 & 6833.39 \\
\hline Flow of the water demanded $\left(\mathrm{m}^{3} / \mathrm{s}\right)$ & 1117.85 & 1193.68 & 1386.46 & 1405.58 & 2382.44 & 2636.34 \\
\hline Month & 7 & 8 & 9 & 10 & 11 & 12 \\
\hline Total water demand $\left(10^{6} \mathrm{~m}^{3}\right)$ & 8814.66 & 8146.31 & 4627.24 & 4309.39 & 3033.06 & 2860.30 \\
\hline Flow of the water demanded $\left(\mathrm{m}^{3} / \mathrm{s}\right)$ & 3291.02 & 3041.49 & 1785.2 & 1608.94 & 1170.16 & 1067.91 \\
\hline
\end{tabular}

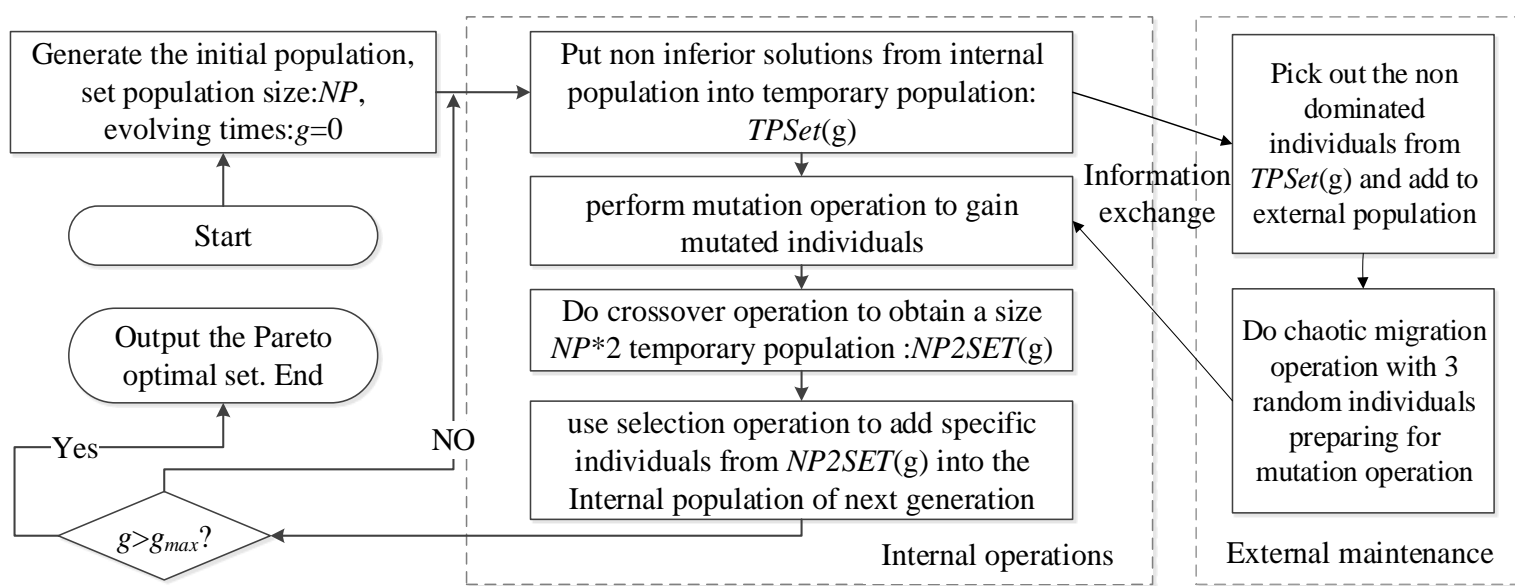

Fig. 2. Flow chart of multi-objective difference algorithm.

\section{Evaluation CRiteria OF WATER SupPly BenEFITS}

As the upper Yangtze River basin is an important zone in China's economic development, the adequate water supply is required. According to the statistical result of the Yangtze Water Resources Commission (the management organization of the Yangtze River), the water demand in the upper reaches in the year 2020 will increase by $16 \%$ comparing with the year 2010. The water demands in 2020 are shown in Table 2.

In order to reflect the water supply benefits, this paper adopts the water supply rate to evaluate the water supply benefit (Eq. 3).

\section{CASE Study}

\section{A. Multi-Objective Difference Evolution}

This paper uses a kind of modified multi-objective differential evolution algorithm (MODE) to solve the optimal dispatch model proposed. Through the external archiving technology [7] and the chaotic sequence [8], the algorithm is designed and the flow chart is shown in Fig. 2.

\section{B. Algorithm Encoding and Objective Fitness}

The water level of the reservoir is an important parameter in the operation of the power station, which can accurately and directly reflect the connections between the power stations in the cascade and is closely related to the complicated constraints (such as water balance, water level amplitude, etc.). In view of this, this paper takes the water level sequence of the dams in the cascade as the variables of the MODE. Each individual in the population is represented as $H=\left(h_{0,1}, \ldots, h_{0 . T}, \ldots, h_{i, t}, \ldots, h_{i, T}\right)$, where $h_{i, t}$ represents the water level of the $i$-th station in the $t$-th period, $T$ is the length of time period. 
In the multi-objective optimal dispatch, the fitness values are normalized respectively to reduce the error caused by different dimensions [9], which is shown below:

$$
f(x)=\frac{x-X_{\min }}{X_{\text {max }}-X_{\text {min }}}
$$

where $X_{\max }$ and $X_{\min }$ are respectively the minimum and maximum fitness values of solutions in the current population; $x$ is the fitness value of the current solution; $f(x)$ is the fitness value after the normalization.

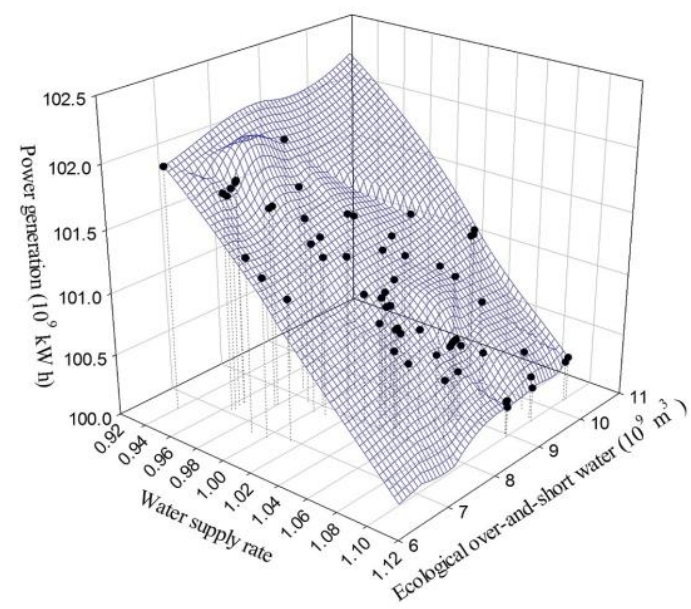

(a)

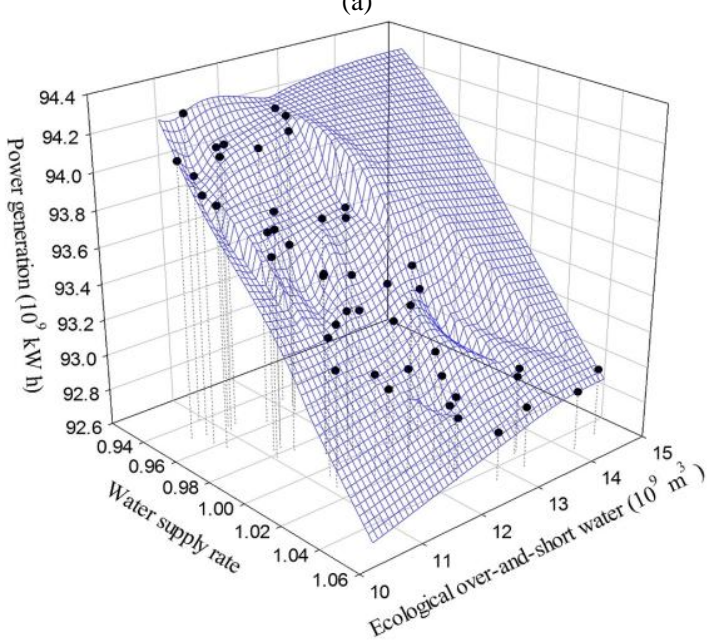

(b)

Fig. 3. Pareto optimal set of $40 \%$ (a) and $60 \%$ (b) typical inflow.

\section{Results and Discussion}

Taking $40 \%$ and $60 \%$ of the inflow of the TGC as the input and dispersing the water supply rate from 0.9 to 1.1 , this paper uses the EWSB-MODM and the MODE to simulate the dispatch operation in year 2020 which is divided into 12 periods (one month for each). The obtained Pareto optimal set about the total generated energy, ecological over-and-short water and water supply rate, as is shown in Fig. 3. The projections of Pareto optimal set in Fig. 3(a) is shown in Fig. 4. Table III shows detailed data of Fig. 3. This paper determines the following parameters in solving this case: the crossover probability factor $\mathrm{Cr}=0.4$, mutation factor $F=0.2$, maximum iteration for the chaotic migration $k m a x=16$, population size $N p=120$, external population size $N a=60$, evolution generations $G N=1500$.

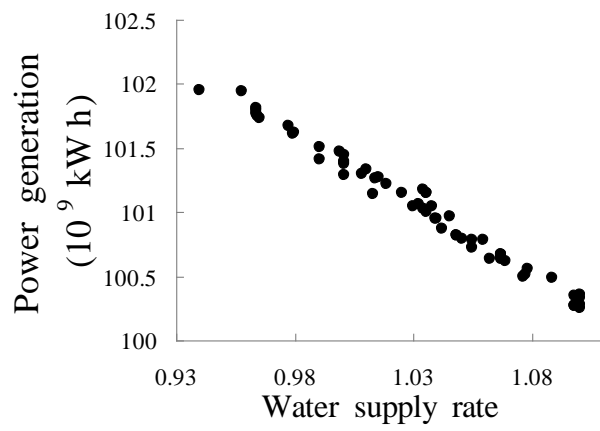

(a)

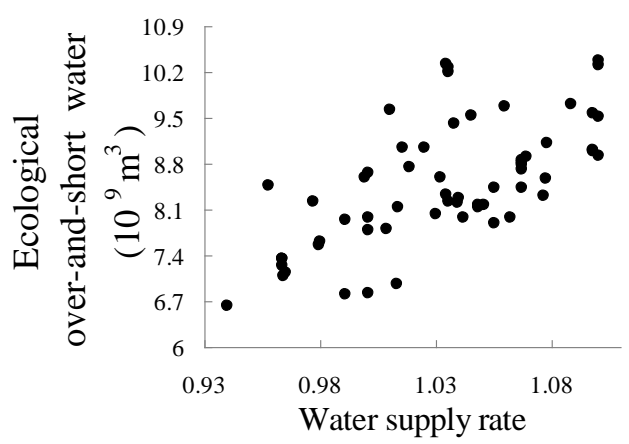

(b)

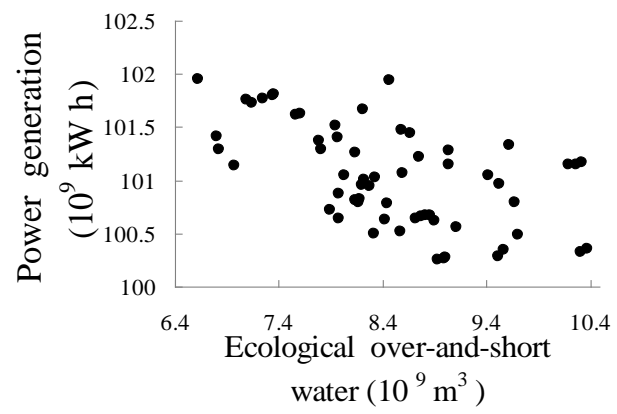

(c)

Fig. 4. The projections of Fig. 3(a).

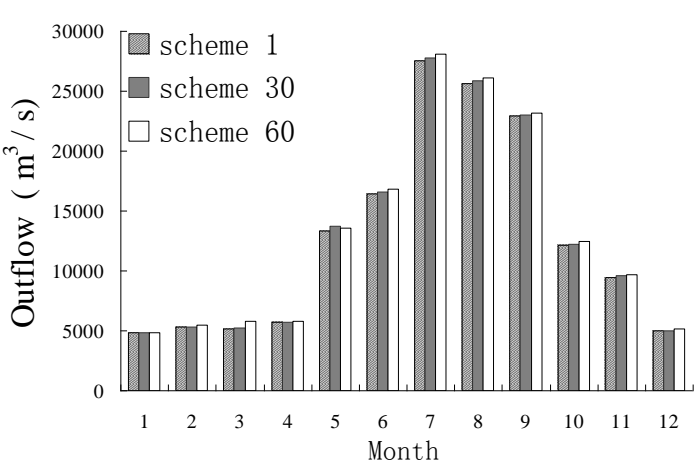

(a)

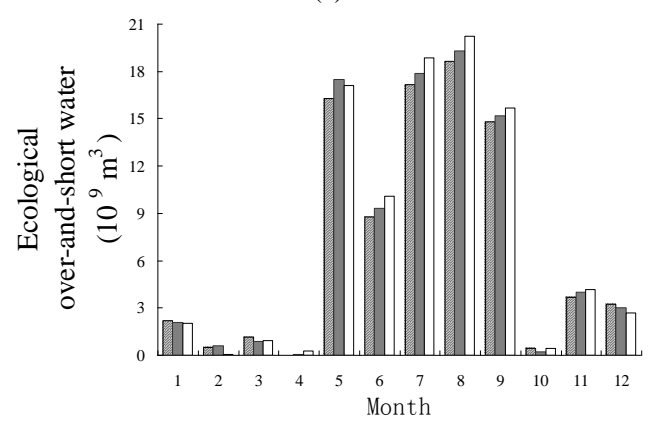

(b) 


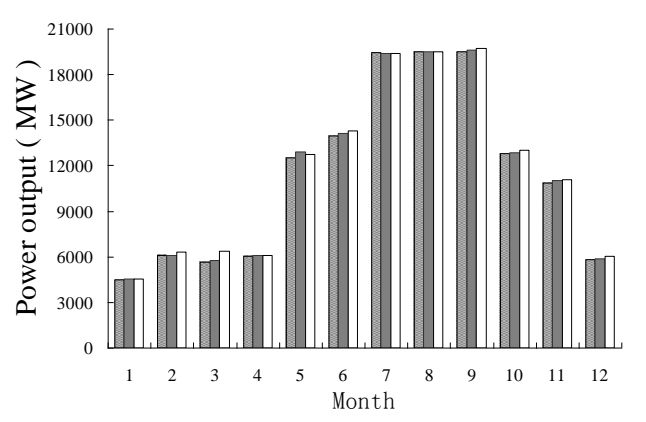

(c)

Fig. 5. The sequences of outflow (a), ecological over-and-short water (b) and power output (c) of NO.1, 30 and 60 schemes.

It can be seen through Fig. 4 that there is clear inverse relation between the cascade generation and the water supply, as they are conflicting and restrict each other. With the increase of power generation, the ecological over-and-short water mainly increases, that is, the ecological benefit reduces, which means that the cascade power generation and the ecological benefit are opposite. With the increase of water supply rate, the ecological over-and-short water mainly increases, which indicates that the water supply benefit and ecological benefit are opposite as well.

The result sequences of the NO.1, 30 and 60 schemes are shown above, the water supply rates are respectively 1.1 , 1.03 and 0.94 . First, in the dry season, the scheme with higher water supply rate has smaller outflow which increases the ecological water shortage, on the contrary, the ecological overflow decreases in the flood season. Secondly, it can be seen from Fig.5 (b) that the high water supply rate makes the power output reduce obviously. Finally, sharp contradiction between ecological and economic benefit is indicated from Fig.5 (a) and (c). This paper uses $40 \%$ and $60 \%$ typical inflows for calculation. It can be seen through Fig. 3 that the value range of $40 \%$ inflow is wider than the $60 \%$ inflow in the power generation, ecological benefit and water supply. So in the case of larger inflow, the cascade can have more space of coordinating and optimizing the dispatch.

\section{CONCLUSIONS}

Taking the generation benefit, ecological over-and-short water and water supply rate as the objective, this paper builds the EWSB-MODM. In addition, this paper formulates the criteria of the ecological benefit for the above model with the monthly frequency method and some key ecological factors in the lower reaches of the Yangtze River. According to the water demands in the upper reaches, this paper also obtains the criteria of the water supply benefit. Finally, this paper introduces the multi-objective differential evolution algorithm to solve the optimal dispatch model, providing a new idea for the reasonable dispatching of water resources.

\section{CONCLUSION}

A conclusion section is usually required. Although a conclusion may review the main points of the paper, do not replicate the abstract as the conclusion. A conclusion might elaborate on the importance of the work or suggest applications and extensions.

\section{REFERENCES}

[1] X. Xu, L. Bin, C. Pan et al., "Optimal reoperation of multi-reservoirs for integrated watershed management with multiple benefits," Water, vol. 6, no. 4, pp. 796-812, 2014.

[2] J. Li, Z. Xia, G. Ma et al., "A new monthly frequency computation method for instream ecological flow," Acta Ecological Sinica, vol. 27, no. pp. 2916-2921, 2007.

[3] Z. Pan, R. Ruan, X. H., and J. Xu, "A new calculation method of instream basic ecological water demand," Shuili Xuebao(Journal of Hydraulic Engineering), vol. 44, no. 1, pp. 119-126, 2013.

[4] F. Cioffi and F. Gallerano, "Multi-objective analysis of dam release flows in rivers downstream from hydropower reservoirs," Applied Mathematical Modelling, vol. 36, no. 7, pp. 2868-2889, 2012.

[5] J. Zhou, Y. Zhao, L. Song et al., "Assessing the effect of the Three Gorges reservoir impoundment on spawning habitat suitability of Chinese sturgeon in Yangtze River, China," Ecological Informatics, vol. 20, no. pp. 33-46, 2014.

[6] Research on ecological security based cascade hydropower dispatch technology, China Institute of Water Resources and Hydropower Research, 2011.

[7] U. Halder, S. Das, and D. Maity, "A cluster-based differential evolution algorithm with external archive for optimization in dynamic environments," IEEE Transactions on Cybernetics, vol. 43, no. 3, pp. 881-897, 2013.

[8] L. Coelho, H. V. H. Ayala, and V. C. Mariani, "A self-adaptive chaotic differential evolution algorithm using gamma distribution for unconstrained global optimization," Applied Mathematics and Computation, vol. 234, no. pp. 452-459, 2014.

[9] H. Qin, J. Zhou, Y. Lu et al., "Multi-objective cultured differential evolution for generating optimal trade-offs in reservoir flood control operation," Water resources management, vol. 24, no. 11, pp. 2611-2632, 2010.

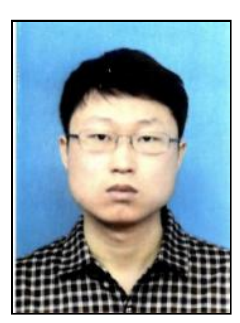

Xuemin Wang received his ME degree in hydraulic and hydro-power engineering from Huazhong University of Science \& Technology (HUST), Wuhan, China in 2011.

He is a PhD student at HUST since 2011, where his topic is related to hydropower generation management and multi-objective optimization. He has worked as a research fellow on a project of optimal operation at the Three Gorges Project (TGP) in 2011. He is also a major member in the key project on hydropower system optimization of the Yangtze River (2012-2015), funded by the National Natural Science Foundation of China (NSFC).

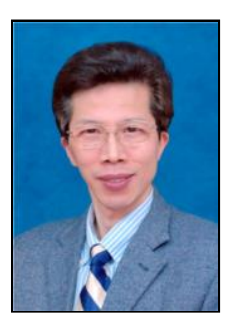

Jianzhong Zhou is a professor in hydropower system at School of Hydropower \& Information Engineering of Huazhong University of Science \& Technology (HUST), Wuhan, China. He is the cadres of several National key basic research projects: "The long-term ecological effects of important biological resources in the Yangtze River Basin (NO.30490230)", "The theory and method on complex system scheduling of reservoir groups in The upper reaches of the Yangtze River (NO. 51239004)" and "The win-win strategy research on Hydropower energy competition in the electricity market (NO. 50579022)".

Prof. Zhou's main research interests include the theory and the method of hydropower energy and its analysis, power generation process control and high-performance network and information system.

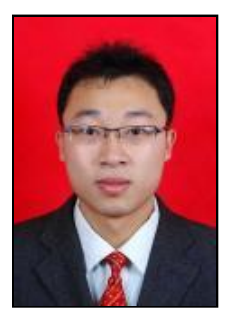

Chao Wang has a bachelor's degree in hydraulic and hydropower engineering from Huazhong University of S\&T (HUST), Wuhan, China in 2011.

$\mathrm{He}$ is a PhD candidate, where his topic is relatied to hydropower system, optimization problem and decision support system. He devotes to a key project funded by the National Natural Science Foundation of China (NSFC) on hydropower system operation optimization of the Yangtze River (2012-2015).

Mr. Wang's main research interests include water resource management, hydropower system operation optimization, intelligence algorithms and decision support system.. 